\title{
Sufentanil blunts the myocardial stress induced by tracheal intubation in older adult patients with coronary heart disease better than equipotent fentanyl
}

\author{
Yanchao Yang, Xiufei Teng, Junchao Zhu \\ Department of Anesthesiology, the Shengjing Hospital, China Medical University, Shenyang, China \\ Contributions: (I) Conception and design: Y Yang, J Zhu; (II) Administrative support: J Zhu; (III) Provision of study materials or patients: X Teng; (IV) \\ Collection and assembly of data: Y Yang; (V) Data analysis and interpretation: Y Yang; (VI) Manuscript writing: All authors; (VII) Final approval of \\ manuscript: All authors. \\ Correspondence to: Junchao Zhu. Department of Anesthesiology, the Shengjing Hospital, China Medical University, 36 Sanhao Street, Shenyang, \\ China. Email: zhujunchao1@hotmail.com.
}

\begin{abstract}
Background: To evaluate the role of sufentanil and fentanyl in the prevention of cardiovascular responses to endotracheal intubation in elderly patients with coronary heart disease (CHD).

Methods: Seventy-one CHD patients scheduled for surgery under general anesthesia were randomly divided into two groups to receive either $0.4 \mu \mathrm{g} / \mathrm{kg}$ of sufentanil (n=35) or $4 \mu \mathrm{g} / \mathrm{kg}$ of fentanyl $(\mathrm{n}=36)$ in a double-blind manner. Under local anesthesia, an invasive arterial catheter is used to monitor systolic blood pressure (SBP), diastolic blood pressure (DBP), and mean arterial blood pressure (MAP). Laryngoscopy and tracheal intubation were successfully performed within 30 seconds. MAP and heart rate (HR) were recorded before anesthesia induction, immediately before intubation, at intubation, and 1, 3, 5 min after tracheal intubation. Rate pressure product (RPP) is calculated by SBP multiple HR.

Results: Patients in the fentanyl group showed a significant increase in MAP, HR, and RPP associated with tracheal intubation. However, the cardiovascular stimulation induced by tracheal intubation was attenuated in the sufentanil group.

Conclusions: Laryngoscope and endotracheal intubation may cause adverse increases in blood pressure (BP) and HR in elderly patients with CHD, resulting in an imbalance of myocardial oxygen consumption and supply and myocardial ischemia. Anesthesia induction with sufentanil $0.4 \mu \mathrm{g} / \mathrm{kg}$ is more potential than fentanyl $4 \mu \mathrm{g} / \mathrm{kg}$ to attenuate the cardiovascular intubation response.
\end{abstract}

Keywords: Sufentanil; fentanyl; tracheal intubation; coronary heart disease (CHD)

Submitted Aug 18, 2020. Accepted for publication Oct 28, 2020.

doi: 10.21037/apm-20-1813

View this article at: http://dx.doi.org/10.21037/apm-20-1813

\section{Introduction}

Coronary heart disease (CHD) is a chronic inflammatory disease, the progression of which can lead to rapid changes in the functional ability of patients with CHD. Laryngoscope and endotracheal intubation cause increased blood pressure (BP) and human resources $(1,2)$. This hemodynamic pressure may lead to an imbalance between myocardial oxygen consumption and supply, thus inducing myocardial ischemia, which may be normal cardiovascular status in durable patients but potentially harmful in patients with CHD. The process of intubation under general anesthesia is a severe stress on the cardiac function of the patient. Therefore, it is essential to reduce cardiovascular stress caused by laryngoscope and endotracheal intubation in high-risk patients. Several drugs have been used to control these hemodynamic changes, including a low dose of fentanyl, local anesthetics, $\alpha$ - or $\beta$-adrenergic blocking agents, and other vasodilators (3-9). 
Sufentanil, a derivative of fentanyl, is found to be the greatest potent opioid that may occur due to its marked U-receptor affinity. Both fentanyl and sufentanil are wildly used to control cardiovascular responses induced by tracheal intubation. In healthy normotensive patients without cardiovascular disease, they showed a similar effect in blunting the cardiovascular changes after the process of tracheal intubation (9-11). However, the efficacy of fentanyl and sufentanil has not yet been compared in patients with abnormal cardiovascular function.

A prospective, randomized, double-blind study was conducted to investigate the different effects of sufentanil and fentanyl on cardiovascular stress during endotracheal intubation in patients with CHD. We present the following article in accordance with the CONSORT reporting checklist (available at http://dx.doi.org/10.21037/apm-201813).

\section{Methods}

This study followed the Declaration of Helsinki (as revised in 2013) and was approved by the Ethics Committee of Shengjing Hospital, Shenyang, Liaoning Province, China (No. 2015PS57J). Written informed consent was obtained from all subjects. Seventy-one CHD patients scheduled for surgery under general anesthesia were randomly allocated to two groups to receive either fentanyl $(n=36)$ or sufentanil $(n=35)$. Coronary angiography in each patient showed lesions in all three major coronary arteries and significant narrowing in at least one major coronary artery $(\geq 75 \%)$. Exclusion criteria were a history of reactive airway disease, gastroesophageal reflux, morbid obesity, a known or predicted difficult airway using a sealed envelope method, patients were randomized to fentanyl or sufentanil groups to receive the following treatments in a doubleblind manner: fentanyl $4 \mu \mathrm{g} / \mathrm{kg}$ or sufentanil $0.4 \mu \mathrm{g} / \mathrm{kg}$. An independent anesthesiologist prepared each treatment, with a maximum of $5 \mathrm{~mL}$ of saline, and the researchers were unaware of the drug's identification. All patients were premedicated intramuscularly with $0.3 \mathrm{mg}$ of scopolamine and $10 \mathrm{mg}$ of morphine thirty minutes before the induction of anesthesia. An intravenous (i.v.) access, five-lead surface electrocardiogram monitoring, pulse oximetry was set up when the patient arrived in the operation room. Then a radial arterial catheter was inserted under local anesthesia for continuous monitoring of BP. HR and BP were recorded as the baseline (T0) when the patient was awake. Then, the anesthesia was induced with $0.02-0.04 \mathrm{mg} / \mathrm{kg}$ of midazolam and $0.2-0.3 \mathrm{mg} / \mathrm{kg}$ of etomidate. Intubation was facilitated with $0.6-0.8 \mathrm{mg} / \mathrm{kg}$ of rocuronium. Subsequently, the tracheal intubation was started 5 min after sufentanil/ fentanyl injection. HR and BP were recorded (T1) before intubation.

During the intubation, the patient's head is placed in the inspiratory position. An experienced anesthesiologist performed intubation using a Macintosh laryngoscope (Timesco, London, UK). Laryngoscopy and endotracheal intubation were completed within 30 seconds. The tracheal tube is inserted into the glottis until the cuff is $1 \mathrm{~cm}$ below the vocal cords, under direct vision. Patients who needed multiple attempts to be successfully intubated were excluded from the statistical analysis. After successful intubation, pulmonary mechanical ventilation was performed using a $100 \%$ oxygen mixture and $1 \%$ inhalation of sevoflurane, with a fresh air flow of $2 \mathrm{~L} / \mathrm{min}$. The ventilator settings were adjusted to maintain the final $\mathrm{CO}_{2}$ level of 4.6-5.2 $\mathrm{kPa}$ (35-40 mmHg). No operations were performed during the observation, including head movement, tube fixation, and surgical field skin preparation. HR and BP were recorded at once after and at 1,3,5 min after tracheal intubation (T2, T3, T4 and T5). The rate pressure product (RPP) is calculated by multiplying SBP by HR.

\section{Statistical analysis}

The quantitative data are expressed as mean \pm SD. Statistical analysis was performed by analysis of variance and Student's $t$-test (paired within groups and unpaired between groups). The qualitative data are expressed as a percent and analyzed by the $\chi^{2}$-test. A P value of $<0.05$ was considered significant.

\section{Results}

The two groups were comparable concerning age, weight, height, gender, and associated disease (Table 1). The preoperative cardiovascular medications were well-matched between the two groups (Table 2). Also, the dosages of midazolam, etomidate, and rocuronium administered during induction in each group were similar. No significant hemodynamic differences on baseline were observed between the two groups.

In the fentanyl group, HR significantly increased from baseline at once after tracheal intubation and remained an elevated level for the following 5 minutes $(\mathrm{P}<0.05)$. However, in the sufentanil group, HR does not significantly increase after tracheal intubation at all the time points 
Table 1 Demographic patient characteristics*

\begin{tabular}{lcc}
\hline Group & Fentanyl $(\mathrm{n}=36)$ & Sufentanil $(\mathrm{n}=35)$ \\
\hline Age (years) & $60 \pm 10$ & $59 \pm 11$ \\
Height (cm) & $169 \pm 5$ & $168 \pm 6$ \\
Weight (kg) & $73 \pm 7$ & $75 \pm 6$ \\
Gender (male/female) & $24 / 12$ & $24 / 11$ \\
Diabetes mellitus (DM) & 9 & 8 \\
Hypertension & 16 & 14 \\
DM combine with hypertension & 7 & 5 \\
\hline
\end{tabular}

${ }^{*}$, values are mean $\pm S D$, or numbers $(n)$.

Table 2 Preoperative administrated cardiovascular medications

\begin{tabular}{lcc}
\hline Group & Fentanyl $(\mathrm{n}=36)$ & Sufentanil $(\mathrm{n}=35)$ \\
\hline$\beta$-adrenergic blockers & 28 & 26 \\
Nitrates & 29 & 28 \\
Calcium channel blockers & 15 & 16 \\
ACEl & 18 & 17 \\
\hline
\end{tabular}

Values are numbers (n).

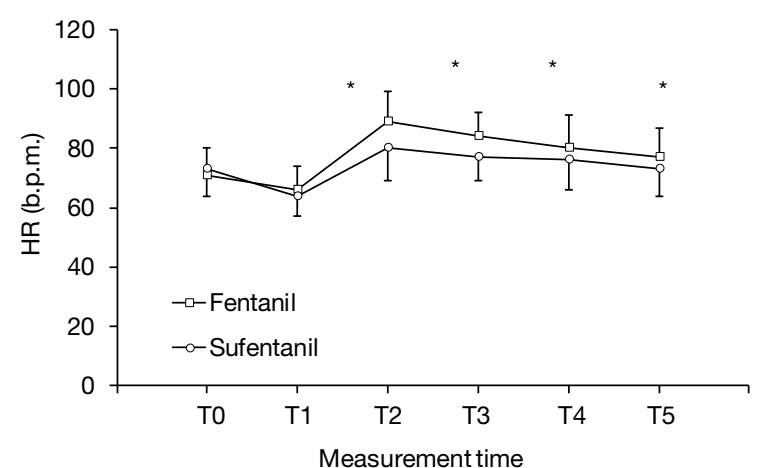

Figure 1 Comparison of HR after intubation in fentanyl group and sufentanil group at each point in time. *, there were statistically significant differences between the fentanyl group and the sufentanyl group in $\mathrm{HR}$ at each time point after intubation $(\mathrm{P}<0.05)$. $\mathrm{HR}$, heart rate.

(Figure 1). However, the MAP increased significantly from baseline immediately after tracheal intubation in the fentanyl group and remained elevated for the following three minutes $(\mathrm{P}<0.05)$, while the increase of MAP was attenuated in the sufentanil group (Figure 2). Additionally,

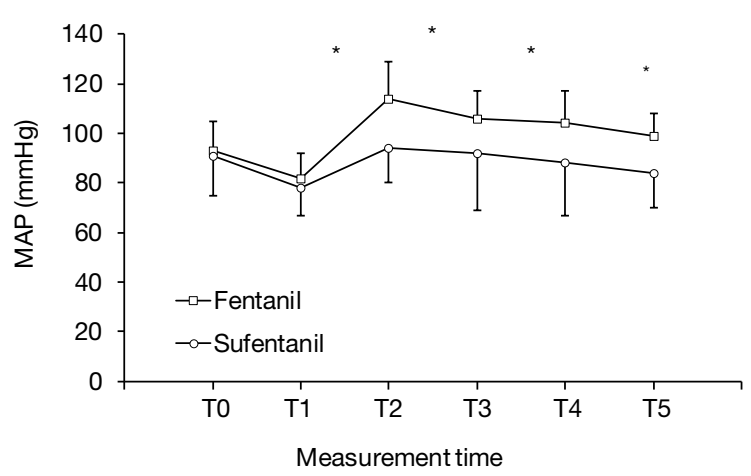

Figure 2 Comparison of MAP after intubation in fentanyl group and sufentanil group at each point in time. *, there were statistically significant differences between the fentanyl group and the sufentanyl group in MAP at each time point after intubation $(\mathrm{P}<0.05)$. MAP, mean arterial blood pressure.

the average level of RPP which reflects myocardial $\mathrm{O}_{2}$ demand was significantly higher than the baseline level after tracheal intubation at all time points in fentanyl-treated patients $(\mathrm{P}<0.05)$, it was, however, maintained at basal level in sufentanil-treated patients (Figure 3). 


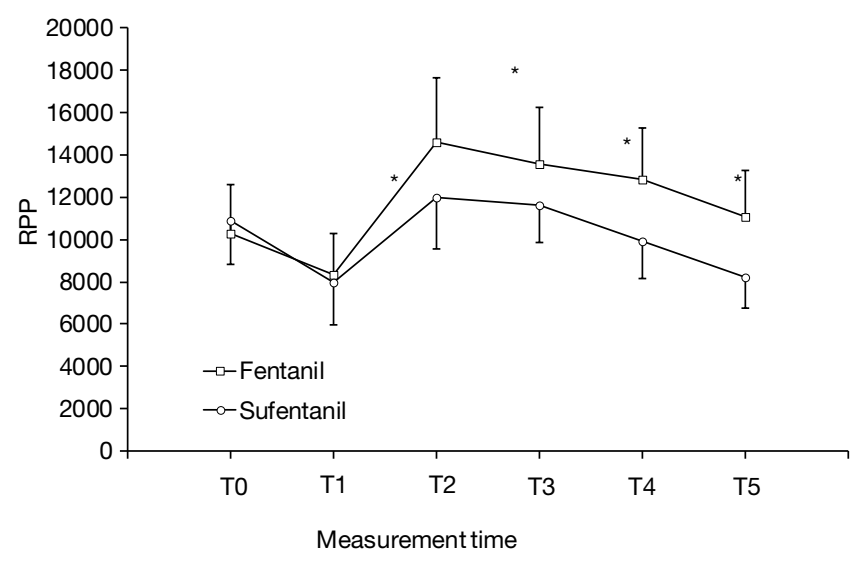

Figure 3 Comparison of RPP after intubation in fentanyl group and sufentanil group at each point in time. *, there were statistically significant differences between the fentanyl group and the sufentanyl group in RPP at each time point after intubation $(\mathrm{P}<0.05)$. RPP, rate pressure product.

\section{Discussion}

Laryngoscopy and tracheal intubation often lead to sympathoadrenal excitement and induce undesirable increases in BP and HR (12). The transient hemodynamic changes are probably of no consequence in healthy individuals. However, they may be dangerous to those with hypertension, myocardial insufficiency, or cerebrovascular disease. Sufentanil has been reported to have fewer hemodynamic effects than fentanyl. It, therefore, is expected to decrease myocardial oxygen consumption and improve myocardial oxygen balance (13). It has been reported that peak effector concentrations of fentanyl and sufentanil took 4-5 minutes after a single injection (14), so in this study, tracheal intubation was started 5 min after sufentanil/ fentanyl injection. Consider the fact that HR is the primary controllable determinant of myocardial oxygen balance (15), the utility of sufentanil to control tachycardia and reduce harmful cardiovascular stimulation induced by tracheal intubation is warranted in clinical practice, particularly in the patients with a high risk of cardiovascular dysfunction.

Choi et al. (16) studied the application of sufentanil in the operation of double-lumen bronchial cannula, and found that $0.3 \mu \mathrm{g} / \mathrm{kg}$ of sufentanil could reduce the cardiovascular reaction of double-lumen bronchial cannula without adverse reactions.

In the previous study, Nazir et al. (17) selected 1,408 children to evaluate the effect of opioids on the reduction of hemodynamic response after endotracheal intubation in pediatric patients under 16 years of age undergoing elective surgery. They observed that $3 \mu \mathrm{g} / \mathrm{kg}$ of remifentanil and $0.3 \mu \mathrm{g} / \mathrm{kg}$ of sufentanil were most effective in suppressing stress responses to intubation, but could lead to hypotension in patients who did not undergo surgical stimulation. Opioid-related side effects and arrhythmias have been observed in few patients.

When myocardial contractility and left ventricular filling, pressure is stable, RPP can well reflect myocardial consumption (18). If RPP $>20,000$, myocardial ischemia may happen. In the fentanyl group, eight patients suffered from RPP >20,000 (30\%) due to tracheal intubation, but only two patients suffered from RPP $>20,000(8 \%)$ in the sufentanil group. This result suggests sufentanil more effectively suppresses myocardial consumption than fentanyl after the process of tracheal intubation. To correctly compare the effects of fentanyl and sufentanil, the two drugs must be used at the same dose. By comparing the data of the sufentanil group and fentanyl group, we found the increase and time of MAP, HR, and RPP during intubation in the fentanyl group was significantly greater than that in the Sufentanyl group. These findings indicate at an equipotent dose, sufentanil but not fentanyl can effectively inhibit an undesirable cardiovascular stimulation as judged by blocking the increase in MAP, HR, and RPP provoked by tracheal intubation in the patients with CHD. Our findings correspond with those of other studies $(19,20)$. The difference in the attenuation of cardiovascular intubation response between the two drugs may be due to the stronger analgesic effect of sufentanil, the more effective reduction of systemic vascular resistance, or the better inhibition of hormonal responses to harmful stimuli $(21,22)$.

It should be pointed out that even though BP in two groups significantly decreased from baseline values after anesthesia induction, only a small proportion of patients (5.6\%) in both groups experienced a decrease in MAP to $<70 \%$ of baseline value, and the observed decreases in MAP values did not require treatment for any subject.

Also, we did not experience opioid-related side effects, for example, bradycardia, a violent cough, or a stiff chest wall.

In conclusion, results of this prospective, randomized, double-blind study demonstrated that, while laryngoscopy and tracheal intubation provoke an undesirable increases in $\mathrm{BP}$ and/or HR, lead to an imbalance between myocardial 
oxygen consumption and supply and induce myocardial ischemia for CHD patients, anesthesia induction with $0.4 \mu \mathrm{g} / \mathrm{kg}$ sufentanil is more potential than fentanyl to attenuate the cardiovascular response.

\section{Acknowledgments}

Funding: None.

\section{Footnote}

Reporting Checklist: The authors have completed the CONSORT reporting checklist. Available at http://dx.doi. org/10.21037/apm-20-1813

Data Sharing Statement: Available at http://dx.doi. org/10.21037/apm-20-1813

Conflicts of Interest: All authors have completed the ICMJE uniform disclosure form (available at http://dx.doi. org/10.21037/apm-20-1813). The authors have no conflicts of interest to declare.

Ethical Statement: The authors are accountable for all aspects of the work in ensuring that questions related to the accuracy or integrity of any part of the work are appropriately investigated and resolved. This study followed the Declaration of Helsinki (as revised in 2013) and was approved by the Ethics Committee of Shengjing Hospital, Shenyang, Liaoning Province, China (No. 2015PS57J). Written informed consent was obtained from all subjects.

Open Access Statement: This is an Open Access article distributed in accordance with the Creative Commons Attribution-NonCommercial-NoDerivs 4.0 International License (CC BY-NC-ND 4.0), which permits the noncommercial replication and distribution of the article with the strict proviso that no changes or edits are made and the original work is properly cited (including links to both the formal publication through the relevant DOI and the license). See: https://creativecommons.org/licenses/by-nc-nd/4.0/.

\section{References}

1. Wang H, Cai Y, Liu J, et al. Pain sensitivity: a feasible way to predict the intensity of stress reaction caused by endotracheal intubation and skin incision? J Anesth 2015;29:904-11.
2. Boschen KE, Criss KJ, Palamarchouk V, et al. Effects of developmental alcohol exposure vs. intubation stress on $\mathrm{BDNF}$ and TrkB expression in the hippocampus and frontal cortex of neonatal rats. Int J Dev Neurosci 2015;43:16-24.

3. Caldwell CD, Watterberg KL. Effect of premedication regimen on infant pain and stress response to endotracheal intubation. J Perinatol 2015;35:415-8.

4. Capuzzo M, Verri M, Alvisi R. Hemodynamic responses to laryngoscopy and intubation: etiological or symptomatic prevention? Minerva Anestesiol 2010;76:173-4.

5. Hancı V, Yurtlu S, Karabağ T, et al. Effects of esmolol, lidocaine and fentanyl on $\mathrm{P}$ wave dispersion, QT, QTc intervals and hemodynamic responses to endotracheal intubation during propofol induction: a comparative study. Braz J Anesthesiol 2013;63:235-44.

6. Oda Y, Nishikawa K, Hase I, et al. The short-acting beta1adrenoceptor antagonists esmolol and landiolol suppress the bispectral index response to tracheal intubation during sevoflurane anesthesia. Anesth Analg 2005;100:733-7, table of contents.

7. Olatosi JO, Ehiozie-Osifo A. Efficacy of intravenous esmolol versus lidocaine for attenuation of the pressor response in nigerians. J West Afr Coll Surg 2016;6:47-69.

8. Tan PH, Yang LC, Shih HC, et al. Combined use of esmolol and nicardipine to blunt the haemodynamic changes following laryngoscopy and tracheal intubation. Anaesthesia 2002;57:1207-12.

9. Friesen RH, Nichols CS, Twite MD, et al. The hemodynamic response to dexmedetomidine loading dose in children with and without pulmonary hypertension. Anesth Analg 2013;117:953-9.

10. Rajbhandari PK. Lignocaine and Esmolol on Stress Response to Laryngoscopy and Intubation. JNMA J Nepal Med Assoc 2014;52:775-9.

11. Schwann NM, Hillel Z, Hoeft A, et al. Lack of effectiveness of the pulmonary artery catheter in cardiac surgery. Anesth Analg 2011;113:994-1002.

12. Pouraghaei $M$, Moharamzadeh $P$, Soleimanpour H, et al. Comparison between the effects of alfentanil, fentanyl and sufentanil on hemodynamic indices during rapid sequence intubation in the emergency department. Anesth Pain Med 2014;4:e14618.

13. Winch P, Khan S, Naguib A, et al. Transportation of patients following surgery for congenital heart disease: a process review prompted by the opening of a new hospital. Int J Clin Exp Med 2014;7:411-5.

14. Soleimani A, Heidari N, Habibi MR, et al. Comparing Hemodynamic Responses to Diazepam, Propofol and 
Etomidate During Anesthesia Induction in Patients with Left Ventricular Dysfunction Undergoing Coronary Artery Bypass Graft Surgery: a Double-blind, Randomized Clinical Trial. Med Arch 2017;71:198-203.

15. Uvizl R, Kolar M, Herkel T, et al. Possibilities for modifying risk factors for the development of hospitalacquired pneumonia in intensive care patients: results of a retrospective, observational study. Biomed Pap Med Fac Univ Palacky Olomouc Czech Repub 2017;161:303-9.

16. Choi BH, Lee YC. Effective bolus dose of sufentanil to attenuate cardiovascular responses in laryngoscopic double-lumen endobronchial intubation. Anesth Pain Med 2016;6:e33640.

17. Nazir M, Salim B, Khan FA. Pharmacological agents for reducing the haemodynamic response to tracheal intubation in paediatric patients: a systematic review. Anaesth Intensive Care 2016;44:681-91.

18. Jagathesan R, Barnes E, Rosen SD, et al. Dobutamineinduced hyperaemia inversely correlates with coronary artery stenosis severity and highlights dissociation between myocardial blood flow and oxygen consumption. Heart 2006;92:1230-7.

19. Xue FS, Liu KP, Liu Y, et al. Assessment of small-dose fentanyl and sufentanil blunting the cardiovascular responses to laryngoscopy and intubation in children. Paediatr Anaesth 2007;17:568-74.

20. Xue FS, Xu YC, Liu Y, et al. Different small-dose sufentanil blunting cardiovascular responses to laryngoscopy and intubation in children: a randomized, double-blind comparison. Br J Anaesth 2008;100:717-23.

21. Bergmann I, Szabanowski T, Bräuer A, et al. Remifentanil added to sufentanil-sevoflurane anesthesia suppresses hemodynamic and metabolic stress responses to intense surgical stimuli more effectively than high-dose sufentanilsevoflurane alone. BMC Anesthesiol 2015;15:3.

22. Zöllner C, Schäfer M. Opioids in anesthesia. Anaesthesist 2008;57:729-40; quiz 41-2.

(English Language Editor: J. Chapnick)
Cite this article as: Yang $\mathrm{Y}$, Teng $\mathrm{X}$, Zhu J. Sufentanil blunts the myocardial stress induced by tracheal intubation in older adult patients with coronary heart disease better than equipotent fentanyl. Ann Palliat Med 2020;9(6):3909-3914. doi: 10.21037/apm-20-1813 